\title{
Review \\ Electrocatalysis for the Oxygen Evolution Reaction in Acidic Media: Progress and Challenges
}

\author{
Hui-Ying $\mathrm{Qu}{ }^{1, * \mathbb{C}}$, Xiwen $\mathrm{He}^{1,2}$, Yibo Wang ${ }^{2}$ and Shuai Hou ${ }^{2, *}$ \\ 1 Guangxi Key Laboratory of Petrochemical Resource Processing and Process Intensification Technology, \\ Guangxi University, Nanning 530004, China; hexiwenhh@163.com \\ 2 Laboratory of Advanced Power Sources, Changchun Institute of Applied Chemistry, Chinese Academy of \\ Sciences, Changchun 130022, China; bowang@ciac.ac.cn \\ * Correspondence: huiying.qu@gxu.edu.cn (H.-Y.Q.); houshuai@ciac.ac.cn (S.H.)
}

Citation: Qu, H.-Y.; He, X.; Wang, Y.; Hou, S. Electrocatalysis for the Oxygen Evolution Reaction in Acidic Media: Progress and Challenges. Appl. Sci. 2021, 11, 4320. https://doi. org/10.3390/app11104320

Academic Editor: Alfio Dario Grasso

Received: 14 April 2021

Accepted: 7 May 2021

Published: 11 May 2021

Publisher's Note: MDPI stays neutral with regard to jurisdictional claims in published maps and institutional affiliations.

Copyright: (c) 2021 by the authors. Licensee MDPI, Basel, Switzerland. This article is an open access article distributed under the terms and conditions of the Creative Commons Attribution (CC BY) license (https:// creativecommons.org/licenses/by/ $4.0 /)$.

\begin{abstract}
The oxygen evolution reaction (OER) is the efficiency-determining half-reaction process of high-demand, electricity-driven water splitting due to its sluggish four-electron transfer reaction. Tremendous effects on developing OER catalysts with high activity and strong acid-tolerance at high oxidation potentials have been made for proton-conducting polymer electrolyte membrane water electrolysis (PEMWE), which is one of the most promising future hydrogen-fuel-generating technologies. This review presents recent progress in understanding OER mechanisms in PEMWE, including the adsorbate evolution mechanism (AEM) and the lattice-oxygen-mediated mechanism (LOM). We further summarize the latest strategies to improve catalytic performance, such as surface/interface modification, catalytic site coordination construction, and electronic structure regulation of catalytic centers. Finally, challenges and prospective solutions for improving OER performance are proposed.
\end{abstract}

Keywords: water electrolysis; acidic oxygen evolution reaction; electrocatalyst; OER activity; metal-support interaction; electronic effect; coordination environment

\section{Introduction}

Searching for sustainable, clean, and highly efficient energy is the main method for solving the energy crisis and environmental pollution problems brought about by the first and second industrial revolutions, which have built a modern and prosperous society based on carbon-based fuels [1-4]. Human actions have led to the carbon dioxide content in the atmosphere rising rapidly and exceeding $400 \mathrm{ppm}$ currently, mostly originating from the burning of coal, oil, and gas [2,5]. The application of wind and solar power and other types of renewable electricity generation technologies seems to be an efficient way to fulfill the requirement of an energy revolution [6-8]. However, they are strongly intermittent in nature due to diurnal or seasonal variations [9]. Converting their energy to a zero-emission chemical energy carrier such as hydrogen is an alternative that can achieve versatile utilization, such as clean heating or electricity at a later stage, on account of the high energy density of hydrogen [5,10-12]. Therefore, an increasing number of sustainable pathways for energy conversion and storage technologies, including water electrolysis, batteries, and fuel cells, have been proposed and extensively investigated [5,13-15]. Proton exchange membrane water electrolysis (PEMWE) operating in acidic environments has offered an effective way to produce sustainable, high-purity hydrogen through targeted electrochemical reactions since the 1960s [16] (Figure 1). PEMWE has the advantages of a faster dynamic response, a higher current density, and lower crossover of gases and is considered to be the basis of a hydrogen society in the future [17-19]. 


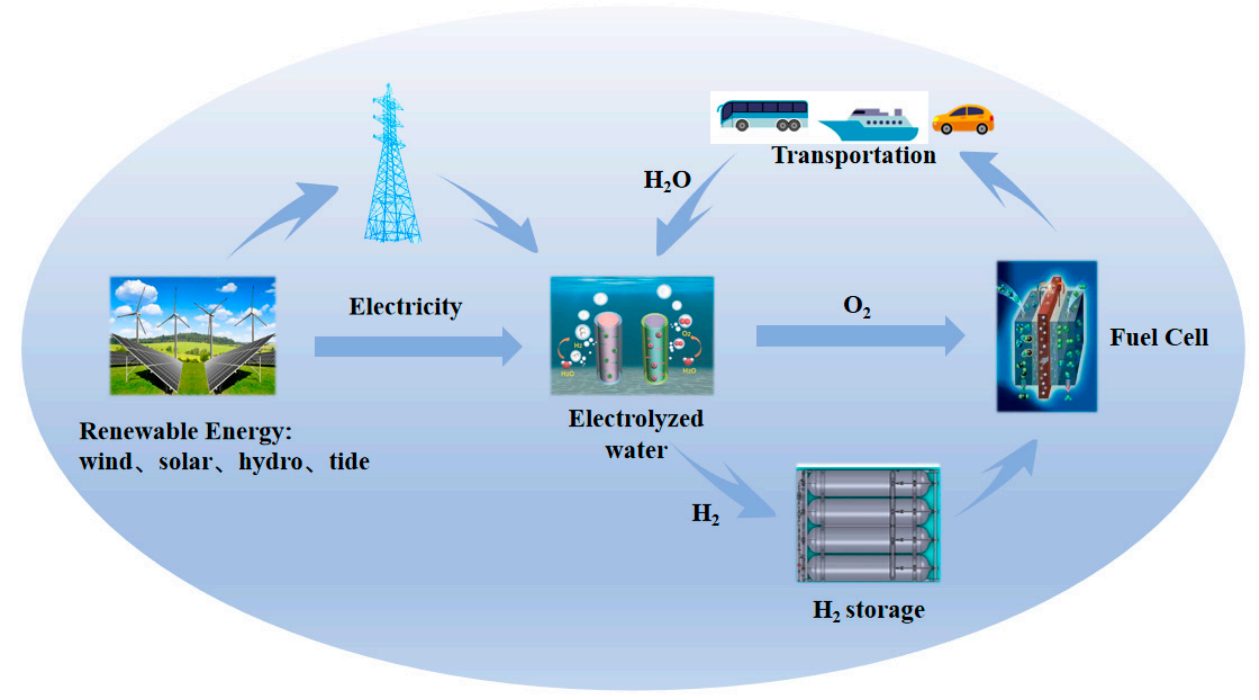

Figure 1. Schematic of sustainable pathways for energy conversion and storage based on electrocatalysis.

Electrochemical water splitting involves two heterogeneous multi-step half-reactions, which are referred to as the cathodic hydrogen evolution reaction (HER) and the anodic oxygen evolution reaction (OER) [20,21]. Owing to the inherent energy barrier, the practical operating voltage of commercial water electrolyzers is higher than the theoretical $1.23 \mathrm{~V}$ (versus a reversible hydrogen electrode) under the standard conditions (298 K and $1 \mathrm{~atm})[22,23]$. For example, industrial electrolytic water generally maintains the external voltage at 1.8 2.0 V [16]. Typically, the descriptor of overpotential is used to show the difference between the thermodynamic potential and the practical potential required to drive the electrochemical reaction [24]. The overpotential mainly comes from the electrochemical polarization on the anode side $\left(\eta_{a}\right)$ and cathode side $\left(\eta_{c}\right)$ and the ohmic polarization caused by other resistors $\left(\eta_{o t h e r}\right)$ [25]. Comparing $\eta_{a}$ and $\eta_{o t h e r}$, the intrinsically sluggish kinetics of the OER involving a four electron-proton coupled reaction (Equation (1)) hampers the overall water-splitting process $[16,26]$.

$$
2 \mathrm{H}_{2} \mathrm{O}(\mathrm{l}) \rightarrow \mathrm{O}_{2}+4 \mathrm{H}^{+}+4 \mathrm{e}^{-}
$$

One solution to this conundrum is to develop suitable catalysts with high efficiency and low overpotential [27]. However, most of the excellent OER catalysts with high activity and durability are not stable in acidic solutions [28]. They are easily oxidized and decomposed in a strong acid system, which is one of the indispensable working conditions for PEMWE [29]. Currently, the iridium (Ir) and ruthenium (Ru)-based electrocatalysts are regarded as the state-of-the-art commercial electrocatalysts for the OER $[30,31]$. Compared with other catalysts, they exhibit excellent OER catalytic activity due to their inherent promising activity, even if severe corrosion still exists under strong acid working conditions [32]. This provides a driving force for the vast majority of studies on the modifications of these electrocatalysts, including composition, structure, and morphology optimizations [23,33-35]. Outstanding OER electrocatalysts should have excellent intrinsic activity and sufficient active sites [18], and these requirements are generally combined with simplicity and controllability. In this regard, optimizations of the reaction energy barrier, electronic conductivity, and reaction surface area of the OER electrocatalysts are of great importance $[18,36,37]$. The transport efficiencies of electrons, ions, and produced oxygen are directly related to the number of channels, which depend on rational surface/interface engineering through nanostructural modifications, such as pore size control and construction of a multi-stage structure $[33,38]$. The nanostructures include zero-dimensional nanoclusters, nanoparticles, nanocages, and nanoframes [39]; one-dimensional nanotubes and nanowires [40]; two-dimensional nanosheets [41]; and three-dimensional nanowire networks, aerogels, etc. [42,43]. Moreover, simple and effective surface/interface engineer- 
ing techniques have been diversified for adjusting the surface atoms, electronic structures, interfacial stresses, and bridge bonds, such as doping elements, tailoring the coordination environment, and loading with active materials [43-46].

Although $\mathrm{Ru} / \mathrm{Ir}$-based electrocatalysts have indeed shown good OER performance, they are still far from ideal OER electrocatalysts in terms of activity and are not completely stable at high oxidative potentials [17,47]. A growing body of evidence shows that Rubased OER catalysts dissolve extensively during the electrocatalytic process [32]. This is because the onset potential of Ru-based catalysts is consistent with the corrosion potential of the metal Ru [48]. Ir-based catalysts also suffer similar degradation issues [49]. During the long-term catalytic process, rutile oxide of $\mathrm{IrO}_{x}$ will transition to other kinds of phases that are soluble in acid media [50]. Therefore, the harsh operating conditions must be taken into account when designing suitable catalysts. Based on this, substantial research efforts have been devoted to investigating the low-precious-metal or precious-metal-free OER catalysts that are stable in acid media, such as perovskite, spinel, and the layer-structuretype family $[23,51,52]$. These kinds of catalysts also exhibit remarkable activity and are low-cost, easily synthesized, and environmentally benign [23].

The field of oxygen evolution has seen significant breakthroughs and notable advancements in the development of highly active electrocatalysts in acidic media, as evidenced by the rapidly increasing number of publications on this subject $[23,53]$. In this review, we begin by presenting OER mechanisms in acid media, which is followed by tailoring strategies for effective OER electrocatalysts, including controlling metal-support interaction, the electronic structure, the coordination environment, and the morphology of the catalysts. Their effects on the activity of the electrocatalysts are highlighted. This review also outlines some recent advances and possible future developments, representing an important perspective for future work.

\section{Mechanisms for the OER in Acidic Media}

In the case of the OER in acid media, two possible mechanisms built on consecutive proton and electron transfers during the catalytic cycle, known as the adsorbate evolution mechanism (AEM) and the lattice oxygen participation mechanism (LOM), have been widely accepted $[24,26,54,55]$ (Figure 2). For the reaction path based on the AEM, a water molecule first adsorbs on a surface metal cation and decomposes into a proton $\left(\mathrm{H}^{+}\right)$to form $\mathrm{HO}^{*}$, which further dissociates the second proton to form $\mathrm{O}^{*}$ in the second step. After that, $\mathrm{HOO}^{*}$ is formed by the nucleophilic attack from another water molecule on the $\mathrm{O}^{*}$. Finally, oxygen is released, accompanied by the desorbed proton. Another four-electron transfer mechanism, known as the LOM, has been proposed based on a series of in-situ isotopic labeling experiments. In contrast to the AEM, lattice O participates in the formation of oxygen for the LOM. Firstly, one water molecule is adsorbed on a surface lattice $\mathrm{O}$ and dissociates the first proton to form $\mathrm{HO}^{*}$, which further dissociates the second proton to form $\mathrm{O}^{*}$ in the second step. After that, oxygen is released via coupling absorbed $\mathrm{O}$ and a surface lattice $\mathrm{O}$ along with the presence of a surface oxygen vacancy. Finally, the surface lattice is restored as before via water adsorption and dissociation on the vacancy [24].

Although both of the mechanisms involve a four-electron transfer, there are still some differences between them [26]. The first one is that the AEM requires a higher reaction energy barrier $(>320 \mathrm{mV})$ than the LOM theoretically [56]. In terms of active sites, the catalytic process predominantly involves a cationic redox (i.e., transition metal ions) in the AEM mechanism and an anion redox (i.e., lattice oxygen) in the LOM [57]. However, it varies according to actual conditions. Jones et al. demonstrated that both mechanisms exist in the OER, which can be detected by the charge storage behavior via the applied bias [58]. At a low bias, it mainly involves the charge storage of metal centers; at a high bias, it involves the storage of oxygen in $\mathrm{IrO}_{\mathrm{x}}$. Moreover, strategies for increasing activity are different based on these two different mechanisms. On basis of the AEM, the active metal centers are always at a lower valence state, which can promote the nucleophilic attack of water molecules by increasing the covalence of metal and oxygen [43]. For 
example, Stoerzinger et al. simulated under-coordinated Ru atoms on a well-crystallized $\mathrm{RuO}_{2}$ surface with superior OER activity [59]. For the LOM, the metal center is often at a higher valence state, which is committed to promoting the generation of more electrophilic oxygen atoms and increasing the interaction between metal and oxygen [60]. Tarascon et al. studied the lattice oxygen behavior of $\mathrm{La}_{2} \mathrm{LiIrO}_{6}$. They believed that Ir was not the active site for the OER owing to the $\mathrm{pH}$-dependent activity [61]. Despite the existing difference, some phenomena occurring in the process of an OER can still be explained by these theories. For example, excessive oxidation of metal sites for the AEM and lattice participation for the LOM generally lead to material instability [49]. Furthermore, the reason why the amorphous metal oxides exhibit better catalytic activity is that lattice oxygen can participate in the catalytic reaction easier than the well-crystallized ones [35].

(a)

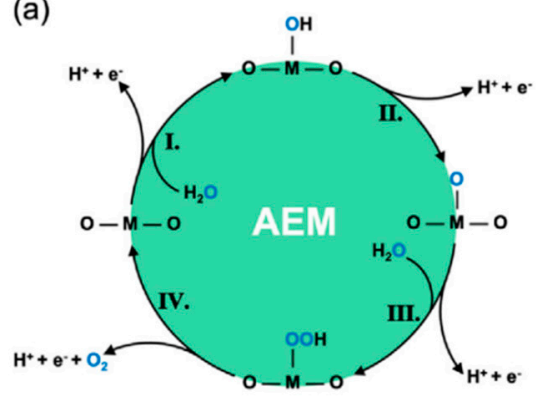

(b)

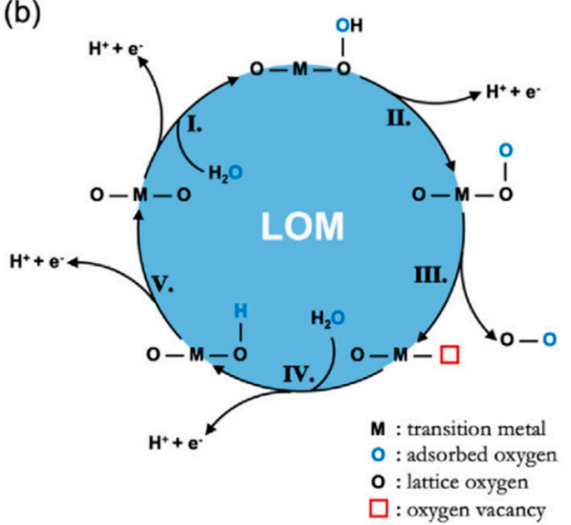

Figure 2. Diagrammatic sketch of (a) the AEM mechanism proposed by Rossmeisl et al. and (b) the LOER mechanism proposed by Rong et al. [24].

It should be mentioned that, apart from increasing the site density, we can also optimize the composition to modify the intrinsic activity of the OER [33,62]. Recent work has pointed out the superiority of bi-metal oxides as some of the most advanced electrocatalysts toward the OER in acidic media, in terms of features including decreased $\mathrm{Ru} / \mathrm{Ir}$ contents and enhanced OER activity and selectivity [23,63]. Incorporating suitable foreign metal atoms, such as $\mathrm{Cr}, \mathrm{Ni}, \mathrm{Zn}$, and $\mathrm{Cu}$ atoms, can surprisingly improve the conductivity and alter the electronic structures of the original catalysts, thus enhancing their intrinsic activity $[64,65]$. It was reported that a low $\mathrm{Ru}$ content oxide material $\left(\mathrm{Cr}_{0.6} \mathrm{Ru}_{0.4} \mathrm{O}_{2}\right)$ derived from a Cr-based metal-organic framework showed remarkable OER performance in acidic media [66]. The superior catalytic activity and stability can be assigned to the lower occupation at the Fermi level and the altered electronic structures by incorporating $\mathrm{Cr}$. Regarding Ni-modified oxides, it is suggested that Ni serves as the sacrificial component, as its leaching generally leads to enhanced OER activity due to the formation of active $\mathrm{OH}$-containing surface structures [67]. For instance, Ni leaching was observed during the OER process of bulk $\mathrm{Ir}-\mathrm{Ni}$ mixed oxides with increased Ni contents (21 atomic\%, 39 atomic\%, and 89 atomic\%), and the remaining $\mathrm{Ni}$ concentrations were similar in all systems, which turned out to be $\sim 12$ atomic\% relative to the total amount of Ir and $\mathrm{Ni}$ in the oxides [68]. However, differences in their OER performance suggested variations in the resulting active sites caused by the sacrifice of $\mathrm{Ni}$. This means that the OER performance of the catalysts is directly related to the transport kinetics of the electrons involved, and the reaction rate is determined also by the number of active sites. Therefore, it is important to prepare electrocatalysts with a sufficient reaction surface area in order to enable facile mass/electron transport and alter the interaction between metals and supports [69]. The most effective way is to minimize the size of catalyst nanoparticles to within several nanometers to make full use of each active site [36]. In addition, composition modification may also increase the number of catalytic sites. Doping $\mathrm{Zn}$ and $\mathrm{Cu}$ can confer moderate binding strength on oxygen intermediates, provide more defects or vacancies to enhance the 
intrinsic activity, and significantly increase the surface area to expose more active reaction sites [70]. However, difficult issues such as well-controlled monodispersity, stabilization of active sites, targeted synthesis, and macro-scale configuration for OER electrocatalysts still remain, especially in acidic media, both experimentally and theoretically $[23,71]$.

\section{Tailoring Strategies for Effective OER Electrocatalysts}

An important frontier in OER electrocatalysis research is the development of the rational design of catalysts [72]. As discussed above, there are generally two strategies to improve catalytic performance: one is to increase the catalyst's intrinsic activity, and the other is to increase the number of exposed active sites by structure/morphology optimization or by increased loading on a given electrode. Ideally, these two strategies are not mutually exclusive and can be addressed simultaneously, thereby leading to significantly improved activity.

\subsection{Metal-Support Interaction}

The interface between the metal center and the support will cause the re-arrangement of electrons originating from the support and anchored atoms [69,73]. The re-arranged electrons that have a significant impact on the catalytic performance will be confined in a space several atomic layers thick at the interface [74]. The magnitude and direction of the charge transfer are driven by differences in the Fermi level of the catalytic center and the support [50]. In addition, due to the special microenvironment at the interface, the interface sites will be in direct contact with the catalytic center, the carrier, and the reactants in order to promote the occurrence of synchronous reactions [37]. Additionally, the interface is conducive to the accumulation of excess charge during the charge transfer process, which will strongly promote the catalytic reactions at the interface [75].

$\mathrm{SnO}_{2}$ and $\mathrm{TiO}_{2}$-based compounds are commonly used as supports due to their characteristic of stability [76,77]. In order to improve their low charge-transfer rate, extensive studies have modified them to improve the conductivity. For $\mathrm{SnO}_{2}, \mathrm{Sb}$ doping is often used to prepare $\mathrm{Sb}-\mathrm{SnO}_{2}$ (ATO), and the conductivity of the material will be improved due to the increased electron carrier density caused by donor doping [78]. Moreover, the specific surface area and pore volume of $\mathrm{SnO}_{2}$ can be improved by destroying the long-range order of the original atomic arrangement so as to provide more anchor sites for $\mathrm{IrO}_{2}$ nanoparticles [77]. The interaction between $\mathrm{IrO}_{2}$ and the support, the cross-linking morphology of $\mathrm{IrO}_{2}$, and the porous structure can improve the OER performance of the catalyst. Wang's group designed a kind of $\mathrm{Sb}-\mathrm{SnO}_{2}$ nanowire carrier by an electrospinning method (Figure 3a) [37]. The conductivity can reach $0.83 \mathrm{~S} \cdot \mathrm{cm}^{-1}$. Compared with pure $\mathrm{IrO}_{2}$, the catalytic activity of supported $\mathrm{IrO}_{2} / \mathrm{Sb}-\mathrm{SnO}_{2}$ exhibits significantly improved mass activity, benefiting from the porous structure and the high electronic conductivity of the $\mathrm{Sb}-\mathrm{SnO}_{2}$ support [37].

In addition to metal oxides, metal carbides have also emerged as promising OER carriers because of their high conductivity and stability. A TaC-supported $\mathrm{IrO}_{2}$ catalyst sprayed by Polonsky et al. showed the lowest charge transfer resistance and the highest current density when the loading of $\mathrm{IrO}_{2}$ reached $70 \mathrm{wt} \%$, which was significantly improved compared with unsupported $\mathrm{IrO}_{2}$ (Figure 3b) [79]. When $\mathrm{TiC}$ is employed as the support for Ir in PEMWE, Ir nanoparticles can be evenly distributed on the TiC surface, and the pore volume of $\mathrm{Ir} / \mathrm{TiC}$ is twice that of pure Ir. All these advantages make the OER catalytic performance of $\mathrm{Ir} / \mathrm{TiC}$ much better than that of pure Ir [80].

In general, the existence of a support has two major advantages. On one hand, catalyst particles can be well dispersed on the support surface and facilitate the construction of a three-phase interface consisting of the catalyst, the reactant water molecule, and the produced oxygen [81]. In fact, this effect has been widely used to explain the increased activity of supported catalysts. For example, Ir nanoparticles can be well dispersed onto the TiN carrier. The $\mathrm{IrO}_{2} @ \mathrm{Ir} / \mathrm{TiN}$ catalyst prepared by Xing's group showed an enhanced catalytic performance [50]. The overpotential was only $265 \mathrm{mV}$ at a current density of 
$10 \mathrm{~mA} \cdot \mathrm{cm}^{-2}$. Yang et al. synthesized iridium dioxide nanoparticle catalysts with $\alpha-\mathrm{MnO}_{2}$ nanorods as supports by a simple two-step hydrothermal method. They found that iridium dioxide nanoparticles were subjected to compressive strain due to the lattice mismatch between $\mathrm{IrO}_{2}$ and $\alpha-\mathrm{MnO}_{2}$ (Figure 3c) [45].

(a)
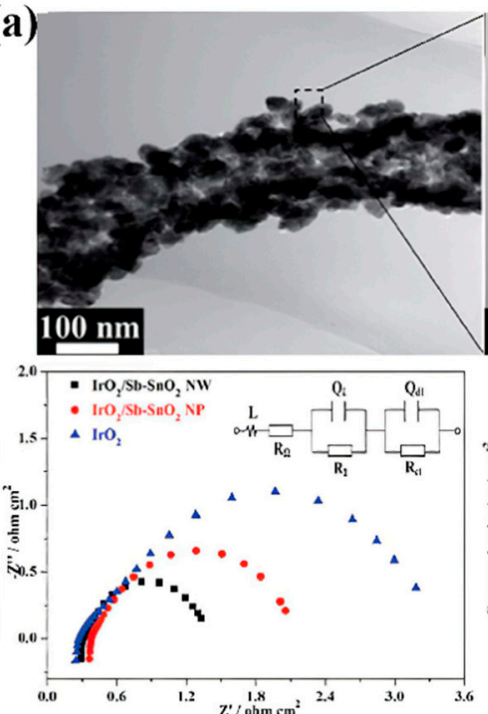

(b)

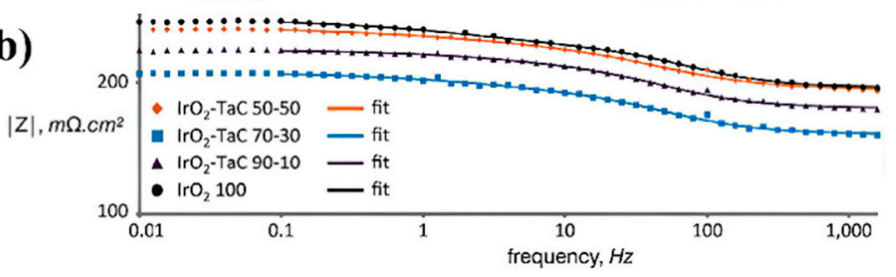

(c)
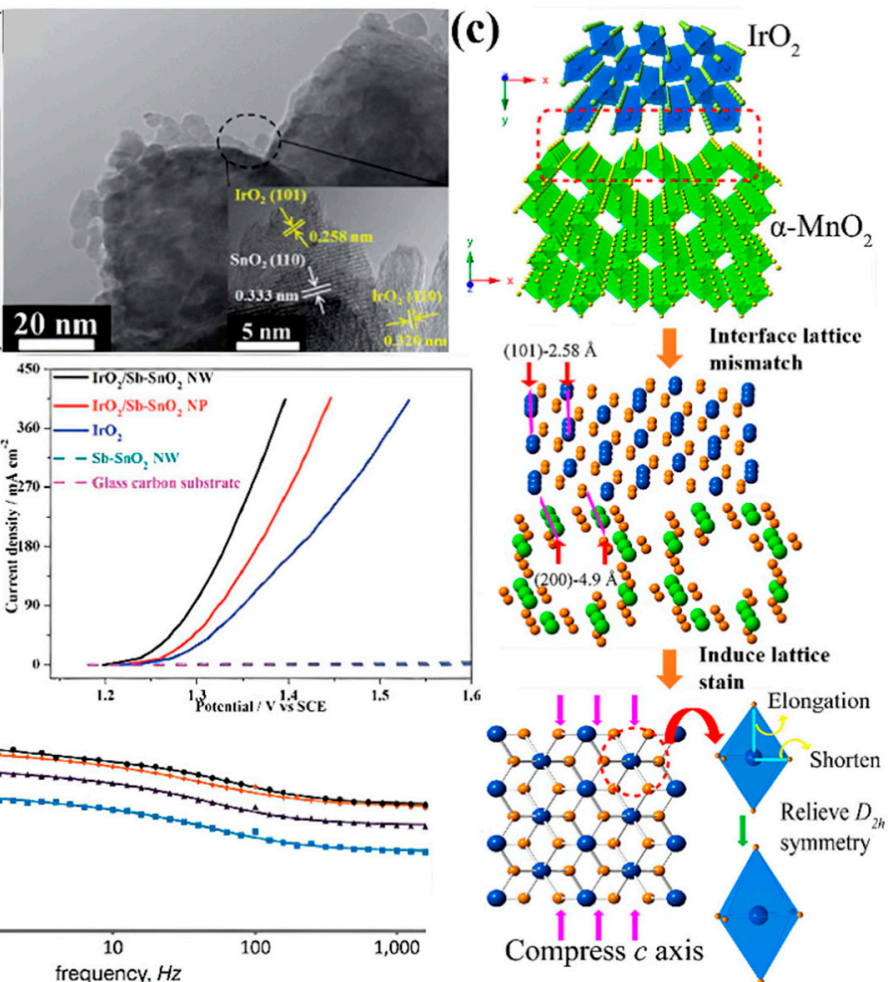

Figure 3. (a) Low- and high-magnification transmission electron microscope (TEM) images, a Nyquist diagram, and the steady-state polarization curve of the $\mathrm{IrO}_{2} / \mathrm{Sb}-\mathrm{SnO}_{2}$ catalyst [37]. (b) Bode plot from the electrochemical impedance spectroscopy (EIS) of TaC-supported $\mathrm{IrO}_{2}$ [79]. (c) Diagram of the process by which the $\alpha-\mathrm{MnO}_{2}$ substrate induces the lattice strain of $\mathrm{IrO}_{2}[45]$.

\subsection{Electronic Structure}

Incorporation of heteroatoms or groups will destroy the periodicity of the lattice, resulting in the modification of the local coordination environment and the electronic structure of active sites [35,82]. This change can effectively regulate the adsorption energy of reaction intermediates and improve the intrinsic activity of electrocatalysts. One of the effective strategies is to incorporate easily soluble non-noble metals, which suffer insitu dissolution to form an amorphous structure, and increase the degree of coordination unsaturation of the metal in the active center during the oxygen evolution reaction [67]. Zaman et al. chose $\mathrm{Ni}$ and $\mathrm{Co}$ as the dopants to substitute $50 \%$ of the precious metal Ir. The Ni-Co co-doped $\mathrm{IrO}_{2}$ showed a low overpotential of $285 \mathrm{mV}$ at a current density of $10 \mathrm{~mA} \cdot \mathrm{cm}^{-2}$ (Figure 4a) [83]. Besides Ir-based catalysts, researchers have also done a lot of work on Ru-based catalysts [84]. For example, $\mathrm{SrRuO}_{3}$ exhibited low OER activity in acid electrolytes due to rapid Sr leaching and Ru dissolution at high potential ranges in $0.1 \mathrm{M}$ $\mathrm{HClO}_{4}$ [85]. Surprisingly, incorporating a small amount of $\mathrm{Na}^{+}$into the lattice of $\mathrm{SrRuO}_{3}$ by substituting $\mathrm{Sr}^{2+}$ results in significantly enhanced OER performance, both in terms of activity and stability (Figure $4 \mathrm{~b}$ ) [86]. The doped sample exhibited $85 \%$ of activity retention after a stability test, which was assigned to the stabilization of Ru centers with a positive shift in dissolution potentials and less distorted $\mathrm{RuO}_{6}$ octahedra.

Preparation of a perovskite $\mathrm{ABO}_{3}$ structure (or $\mathrm{A}_{2} \mathrm{BB}^{\prime} \mathrm{O}_{6}$ ) and regulation of the valence band structure of B-site cations (usually Ir and $\mathrm{Ru}$ ) by the atoms at A-site cations have commonly been used to improve the performance of the OER in recent years. Catalysts with 
this perovskite structure can greatly reduce the usage of noble metals. Pseudocubic $\mathrm{SrIrO}_{3}$ was the first $\mathrm{AIrO}_{3}$ single perovskite oxide reported for usage as an OER electrocatalyst in acid media [87]. It was found that the formation of $\mathrm{IrO}_{x}$ by Sr leaching on the surface of $\mathrm{SrIrO}_{3}$ through surface reconstruction was responsible for the enhanced OER activity (Figure $4 c$ ). The active surface area increased significantly owing to the formation of $\mathrm{IrO}_{\mathrm{x}}$ groups on the surface of catalysts during cycling. Moreover, the intrinsic activity of Ir in the $\mathrm{SrCo}_{0.9} \mathrm{Ir}_{0.1} \mathrm{O}_{3-\delta}$ electrocatalyst was more than two orders of magnitude higher than that of $\mathrm{IrO}_{2}$ and approximately 10-fold higher as compared with the unmodified benchmark $\mathrm{SrIrO}_{3}$ [88]. The observed high activity was attributed to the surface reconstruction through $\mathrm{Sr}$ and Co leaching during the electrochemical cycling, which contains a large number of oxygen vacancies with corner-shared and under-coordinated $\mathrm{IrO}_{\mathbf{x}}$ octahedrons in the oxide crystal lattice. Furthermore, surface reconstruction of $\mathrm{AIrO}_{3}(\mathrm{~A}=\mathrm{Sr}$ or $\mathrm{Ba})$ perovskite oxides was visualized by atomic-resolution scanning transmission electron microscopy (Figure 4d) [89]. Leaching of Sr or Ba happened by applying an anodic current, resulting in surface roughening and a structure change by the continuous formation of the mosaic-shaped, Sr-deficient $\mathrm{IrO}_{\mathrm{x}}$ on the surface. Moreover, the lattice strain induced by the substitution of smaller lanthanides or yttrium atoms can effectively decrease the adsorption energy toward oxygen-containing intermediates [51]. Although promising in terms of providing enhanced activity, such a surface reconstruction during the electrocatalysis process may be challenged by the uncertainty of the exact structure formed during reactions [87].

(a)
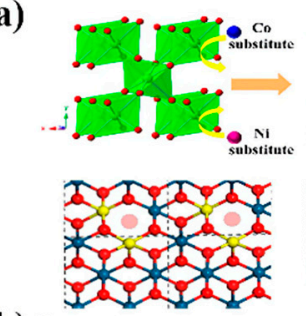

(b)
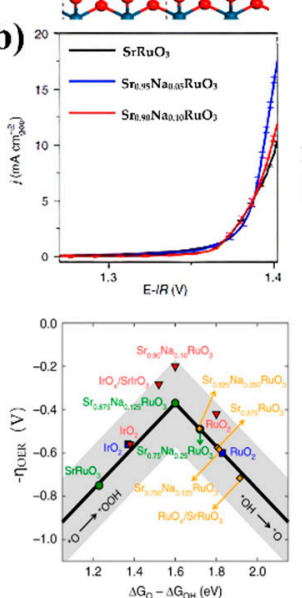
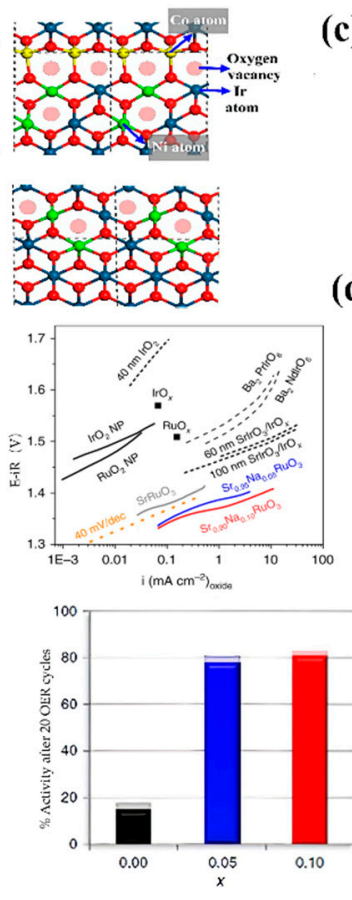

(c)

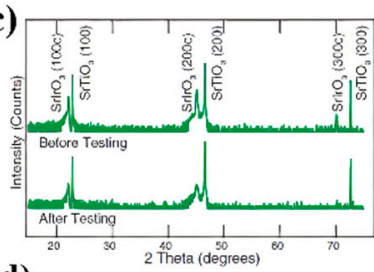

(d)

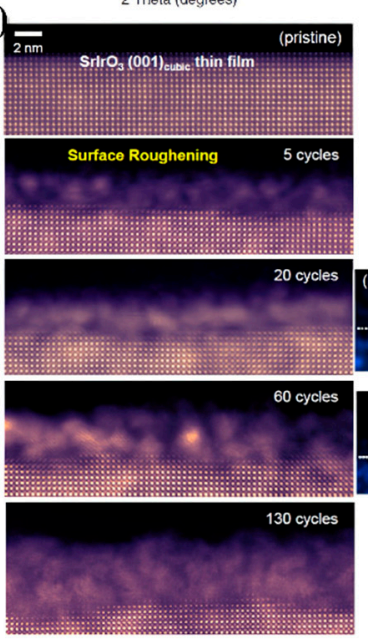

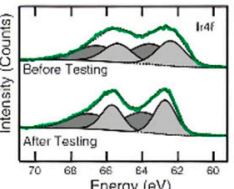
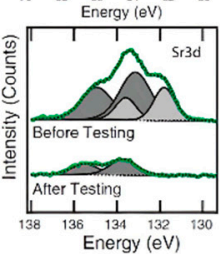

Energy (eV)

Figure 4. (a) Polyhedral model of $\mathrm{IrO}_{2}$ being doped with $\mathrm{Ni}$ and $\mathrm{Co}$ [83]. (b) Enhanced OER activity and durability of $\mathrm{SrRuO}_{3}$ by Na doping [86]. (c) XRD and XPS spectra of a $\mathrm{SrIrO}_{3}$ film before and after $30 \mathrm{~h}$ of OER testing [87]. (d) High-angle annular dark-field (HAADF) images of the surface structural evolution of $\mathrm{SrIrO}_{3}$ film during the OER [89].

It should be mentioned that different kinds of crystal structures have a significant impact on the OER performance. It was proposed that monoclinic $\mathrm{SrIrO}_{3}$ underwent less surface reconstruction than the pseudocubic $\mathrm{SrIrO}_{3}$ owing to the better thermodynamic stability during OER tests in an acidic electrolyte [90]. Strong Ir-Ir metallic bonding and $\mathrm{Ir}-\mathrm{O}$ covalent bonding in monoclinic $\mathrm{SrIrO}_{3}$ together induced its high structural and compositional stability. Only about $1 \%$ of the leached $\mathrm{Sr}$ was detected after $30 \mathrm{~h}$ in a 
chronopotentiometry test, which was much less than that (24\%) from the pseudocubic $\mathrm{SrIrO}_{3}$. Additionally, Zou et al. put forward another way to decrease the cation leaching and surface reconstruction of pseudocubic $\mathrm{SrIrO}_{3}$ in acid media. They prepared pseudocubic, low-Ir-containing $\mathrm{SrIr}_{\mathrm{x}} \mathrm{Ti}_{1-\mathrm{x}} \mathrm{O}_{3}$ perovskite oxides with $0 \leq \mathrm{x} \leq 0.67$. The inert Ti sites in pristine $\mathrm{SrTiO}_{3}$ were activated by Ir-substitution and showed remarkable OER activity with a reserved crystal structure of $\mathrm{Ir}-\mathrm{SrIrO}_{3}$ during OER cycling [91].

For metal alloy /oxide-based electrocatalysts, the surface oxidation of metal atoms accompanied by de-alloying (surface dissolution of unstable metals) under acid OER conditions is considered to be a "surface engineering" strategy to design stable and efficient OER electrocatalysts. For example, Travis Jones and Peter Strasser found that electrochemical de-alloying and surface oxidation treatment of $\mathrm{IrNi}_{3.2}$ nanoparticle precursors can lead to the dissolution of $\mathrm{Ni}$, and the formed $\mathrm{Ni}$ nanoparticles showed better catalytic performance than core-shell-structured $\mathrm{IrNi}_{\mathrm{IrO}} \mathrm{Ir}_{\mathbf{x}}$ [57]. In order to investigate the relationship between the reconstructed structure and the enhanced OER performance, an operando X-ray absorption spectroscopy (XAS) analysis was performed to characterize the local electronic properties under the OER process. The results show that iridium titania and d-band holes appear in the $\mathrm{IrNiO}_{x}$ electrocatalyst when the potential increases from 0.4 to $1.5 \mathrm{~V}_{\mathrm{RHE}}$. More importantly, due to the higher oxidation state of iridium, the iridium oxygen bond length in $\mathrm{IrNiO}_{\mathrm{x}}$ was significantly shortened. Based on this unique phenomenon, a structural model of the iridium oxygen ligand environment was proposed. The model shows that the hole-doped iridium ion sites around the electrophilic oxygen ligands form hole-doped $\mathrm{IrO}_{x}$ (caused by Ni leaching) during the OER. Therefore, more electrophilic oxygen ligands are susceptible to the nucleophilic attack of water molecules or hydroxyl ligands, resulting in the formation of oxygen bonds and the reduction of the kinetic energy barrier, which ultimately greatly improves the reaction activity.

\subsection{Coordination Environment}

Although great efforts have been made to improve the efficiency of OER electrocatalysts, the majority of active sites inside their bulk phases remain inaccessible [23]. In order to maximize the utilization of each active site (approaching 100\%) as well as shed light on the effect of the structure of active centers and ligating atoms on the OER activity, catalysts have thus been continuously downsized to the single-atom (SA) level. Single-atom catalysts (SACs) have emerged as a hot new branch of heterogeneous catalysts due to their excellent catalytic performance and financial benefits [28]. Owing to the high requirements for the dispersion, activity, and stability of the atoms, an appropriate support must be selected to optimize the physiochemical properties of the metal atoms anchored [81]. The unique coordination configuration of the dispersed metal atoms and coordinating atoms together create active sites for OER catalysts; therefore, the coordination-activity relationship has a strong impact on the catalytic performance [92]. In fact, targeted synthesis of precious metal single-atom-based OER electrocatalysts remains a bottleneck and has been pursued in the search for better OER catalysis, especially under acid conditions [28]. Generally, carbon supports often suffer severe corrosion problems under acid conditions and oxide supports are not always conductive, which brings about huge trouble for the design of single-atom catalysts [93]. In order to solve these problems, a series of $\mathrm{Pt}-\mathrm{Cu}$ alloys with an atomically dispersed $\mathrm{Ru}_{1}$ decoration were studied by Yao et al. [94]. An ultralow overpotential of $170 \mathrm{mV}$ at a current density of $10 \mathrm{~mA} \cdot \mathrm{cm}^{-2}$ was reached by $\mathrm{Ru}_{1}-\mathrm{Pt}_{3} \mathrm{Cu}$ in acid media, together with a ten times longer lifetime than a commercial $\mathrm{RuO}_{2}$ catalyst. Density functional theory calculations suggested that the electronic structure of single Ru sites at the corner or step sites of the Pt-rich shell was modulated by the compressive strain in the Pt skin shell, contributing to the optimized binding of oxygen species and improved resistance to over-oxidation and dissolution. Yin et al. demonstrated that surface-exposed Ir single atom couplings with oxygen vacancies anchored in ultrathin $\mathrm{NiCo}_{2} \mathrm{O}_{4}$ porous nanosheets exhibited remarkable OER activity and stability in acid media, with an overpotential of only $240 \mathrm{mV}$ at a current density of $10 \mathrm{~mA} \cdot \mathrm{cm}^{-2}$ and a long-term durability of $70 \mathrm{~h}$ [28]. 
Based on density functional theory calculations, high electronic exchange and transfer activities of the surface contributed by Ir atoms anchored at Co sites near oxygen vacancies were determined to be responsible for the prominent OER performance (Figure 5). The synergetic mutual activation between $\mathrm{Ir}$ and $\mathrm{Co}$ reached the desired $\mathrm{H}_{2} \mathrm{O}$ activation level and stabilized ${ }^{*} \mathrm{O}$ to boost OER performance.
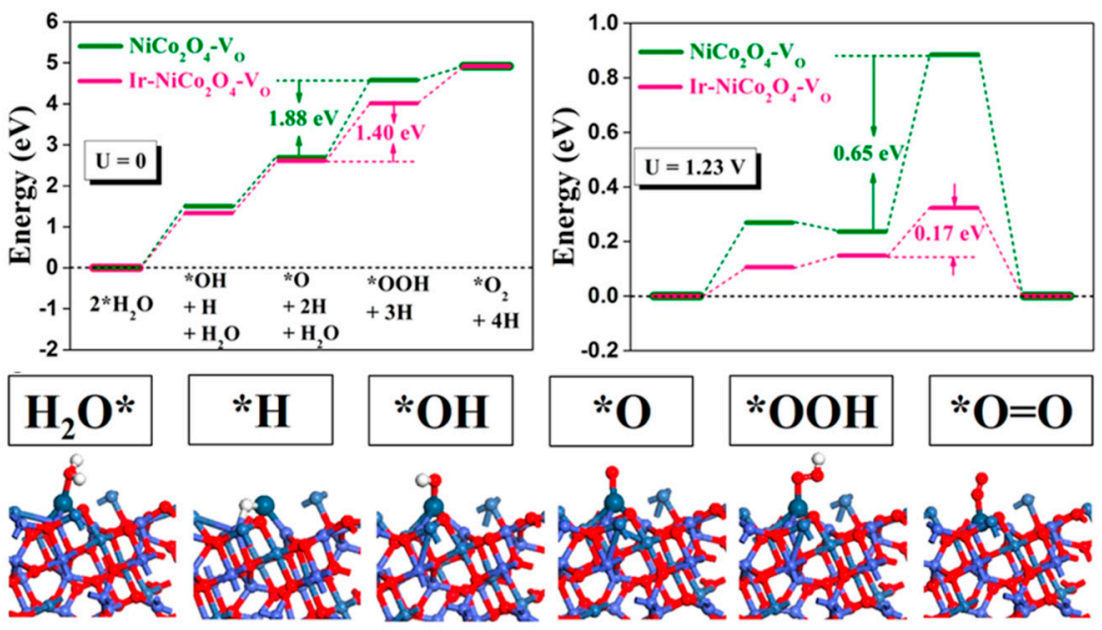

Figure 5. OER pathway under acidic conditions and local structural configurations of intermediates on the $\mathrm{Ir}-\mathrm{NiCO}_{2} \mathrm{O}_{4}-\mathrm{V}_{\mathrm{O}}[28]$.

\subsection{Morphology}

The interface between the catalyst and the electrolyte plays an important role in water electrocatalysis [95]. As a very important aspect of a surface structure, morphology has attracted much attention in recent years $[23,96]$. To date, many methods to control the morphology have been proposed [23,62].

The morphology of the catalyst can be modified by adopting a suitable preparation strategy, such as the template method, the solvothermal method, or the seed crystal method $[97,98]$. A nano-porous or ultra-thin structure can increase the number of exposed active sites. Luo et al. prepared a new kind of Ir nanowire with a diameter of $1.7 \mathrm{~nm}$ by a wet chemical method (Figure 6a) [62]. Due to the high aspect ratio and large specific surface area, the OER activity increased greatly. The overpotential at $10 \mathrm{~mA} \cdot \mathrm{cm}^{-2}$ in $0.5 \mathrm{M}$ $\mathrm{HClO}_{4}$ is only $270 \mathrm{mV}$, which is significantly higher than that of Ir nanoparticles.

In fact, the electronic structure of catalytic centers can be modified by defects as well as the morphology. For example, Qiao et al. prepared a core-shell $\mathrm{Ru} @ \mathrm{IrO}_{\mathrm{x}}$ icosahedral nanocrystal structure by the sequential polyol method, in which a highly distorted lattice can be observed (Figure 6b) [99]. Due to the interaction between the ruthenium core and the iridium shell, ruthenium is subjected to compressive strain, which was confirmed by the decrease in the distance between ruthenium and ruthenium atoms observed by EXAFS. This strain may lead to a shift in the d-band center, which can regulate the binding energy of oxygen intermediates and the activity of the OER. In addition to the lattice strain, morphology control can also lead to changes in the chemical composition, which directly affects the electronic structure. An example is the ultra-thin ruthenium oxide nanosheets prepared by Lotsch's group (Figure 6c) [100]. Owing to the acid treatment in the stripping process, the actual composition of ruthenium oxide is $\mathrm{H}_{\mathrm{x}} \mathrm{RuO}_{2}$, in which the valence of ruthenium is $+3 /+4$. Therefore, ruthenium oxide nanoparticles exhibit enhanced OER activity and stability. 
(a)
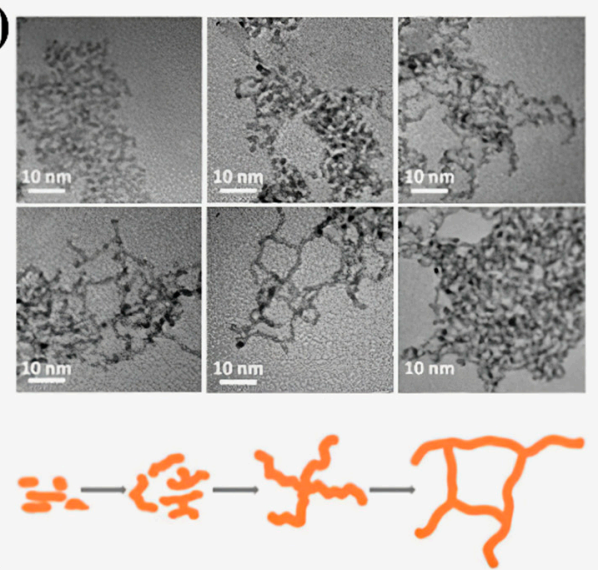

(c)
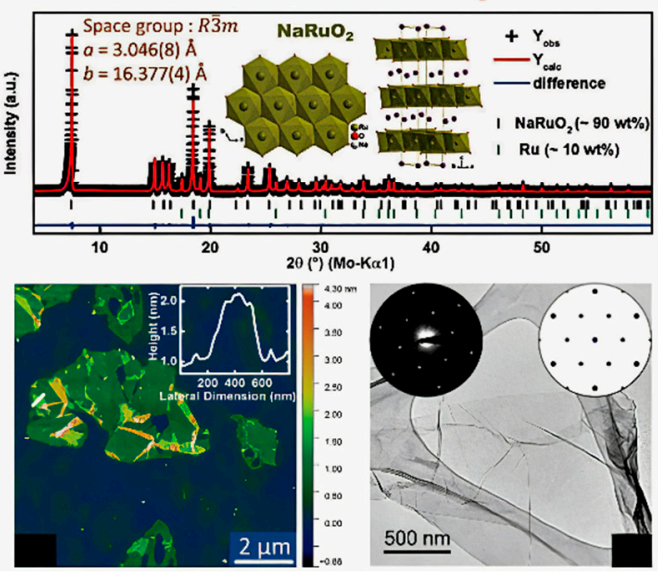

(b)
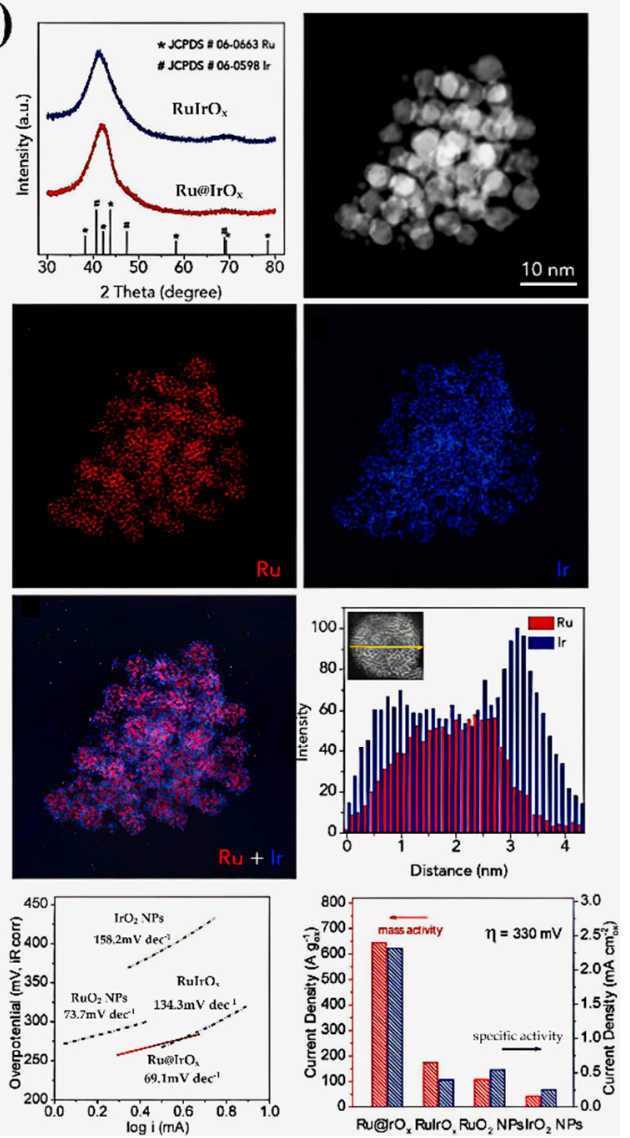

Figure 6. (a) TEM images and a schematic illustration of Ir nanowire intermediates obtained at different reaction times from 5 min to 20 h [62]. (b) Fine-structure characterization of a $\mathrm{Ru} @ \mathrm{IrO}_{\mathrm{x}}$ catalyst and investigation of its OER electrocatalytic activity [99]. (c) Fine-structure characterizations of ultra-thin $\mathrm{NaRuO}_{2}$ nanosheets including the crystal structure, an atomic force microscopy (AFM) image, a TEM image, and selected area electron diffraction (SAED) patterns [100].

\section{Summary and Outlook}

The rational design of a catalyst to improve its activity and stability in acidic systems is an important prerequisite and basis for the realization of PEMWE. This review not only surveyed our fundamental understanding of the OER, but also summarized the optimization strategies to optimize the catalyst's performance under acidic systems. Through the investigation of the available reports, some general principles for the design and preparation of potential catalysts were reviewed. As more and more effort is devoted in the development of OER catalysts under acidic conditions, the work in this area has made rapid progress. The performance of OER catalysts is getting closer to practicality. However, more and more problems have come along with the progress. Greater efforts should be made on the basis of the following aspects.

Research on precious-metal-free OER catalysts has not made a substantial breakthrough owing to the harsh working conditions. Research on the OER in acid media is mostly focused on noble-metal-based electrocatalysts, such as Ir/Ru-based materials. Even $\mathrm{RuO}_{2}$ will dissolve during the catalysis process due to phase inversion. Perovskite oxides seem to be promising candidates to replace the noble-metal-based electrocatalysts. However, some questions remain to be solved. For example, most of the perovskite catalysts with high OER activity in acidic solutions are not really precious metal free, as their B-sites require the participation of precious metals. Furthermore, in depth study on overcoming the continuous leaching and dissolution problems of these kinds of catalysts under harsh working conditions is still required. All in all, tremendous efforts should be devoted to 
improving the performance of nonprecious-metal-based catalysts, including the intrinsic activity as well as corrosion resistance in an acid environment at high oxidation potentials.

Accurate detection of reaction intermediates is an important prerequisite for the establishment of mechanisms. However, limited by the temporal and spatial resolution of the current characterization equipment, direct experimental evidence for the proposed OER mechanisms and active sites in acid media is still limited despite the many different proposed reaction mechanisms. Recently, more and more evidence has revealed that the reaction mechanism of the OER varies with different catalysts in an acidic environment. Moreover, the structure of catalytic centers seems to change during the electrocatalytic process, which greatly increases the difficulty of identifying the mechanism. At present, most of the studies on the evolution of reaction intermediates and reaction centers are realized through density functional theory simulations accompanied by experimental results. However, we need to find correlations between different reaction mechanisms, so as to provide a strong foundation for the rational design of catalysts. Driven by this goal, more in situ characterization techniques, such as in situ XAS, in situ diffuse reflectance infrared Fourier transform (DRIFT) spectra, and femtosecond spectra, should be developed to enable us to understand the reaction mechanism more deeply. In addition, isotopelabeled electrochemical mass spectroscopy (DEMS) is another powerful tool to explore the mechanism of the reaction. Only in this way can great progress be made to promote a deeper understanding of the mechanism.

We believe that opportunities and challenges coexist. Through this review, we have summarized the latest achievements in the field of the OER in acid media. We hope to attract more researchers to jointly promote the progress of water electrolysis technology in the future.

Author Contributions: Writing—original draft preparation, H.-Y.Q. and X.H.; writing—review and editing, Y.W. and S.H. All authors have read and agreed to the published version of the manuscript.

Funding: This research received no external funding.

Institutional Review Board Statement: Not applicable.

Informed Consent Statement: Not applicable.

Acknowledgments: The authors are grateful for the financial support from the National Natural Science Foundation (No. 21905267, 52002087), the Natural Science Foundation of Guangxi Province (No. 2020GXNSFBA297002), the Chinese Central Government Guided Local Science and Technology Development Project (No. Guike AD20238064), the Opening Project of Guangxi Key Laboratory of Petrochemical Resource Processing and Process Intensification Technology (No. 2018k011), and the special funding for 'Guangxi Bagui Scholars'.

Conflicts of Interest: The authors declare no conflict of interest.

\section{References}

1. Cook, T.R.; Dogutan, D.K.; Reece, S.Y.; Surendranath, Y.; Teets, T.S.; Nocera, D.G. Solar Energy Supply and Storage for the Legacy and Nonlegacy Worlds. Chem. Rev. 2010, 110, 6474-6502. [CrossRef]

2. Suen, N.T.; Hung, S.F.; Quan, Q.; Zhang, N.; Xu, Y.J.; Chen, H.M. Electrocatalysis for the oxygen evolution reaction: Recent development and future perspectives. Chem. Soc. Rev. 2017, 46, 337. [CrossRef]

3. Benson, E.E.; Kubiak, C.P.; Sathrum, A.J.; Smieja, J.M. Electrocatalytic and homogeneous approaches to conversion of $\mathrm{CO}_{2}$ to liquid fuels. Chem. Soc. Rev. 2009, 38, 89-99. [CrossRef]

4. Turner, J.A. Sustainable hydrogen production. Science 2004, 305, 972-974. [CrossRef]

5. Chu, S.; Majumdar, A. Opportunities and challenges for a sustainable energy future. Nature 2012, 488, 294-303. [CrossRef]

6. Reier, T.; Nong, H.N.; Teschner, D.; Schlögl, R.; Strasser, P. Electrocatalytic Oxygen Evolution Reaction in Acidic EnvironmentsReaction Mechanisms and Catalysts. Adv. Energy Mater. 2017, 7, 1601275. [CrossRef]

7. Wang, Y.; Yu, X.; Yin, M.; Wang, J.; Gao, Q.; Yu, Y.; Cheng, T.; Wang, Z.L. Gravity triboelectric nanogenerator for the steady harvesting of natural wind energy. Nano Energy 2021, 82, 105740. [CrossRef]

8. Surya Prakash, V.; Manoj Kumar, G.; Gouthem, S.E.; Srithar, A. Solar powered seed sowing machine. Mater. Today Proc. 2021. [CrossRef] 
9. Wei, C.; Rao, R.R.; Peng, J.; Huang, B.; Stephens, I.E.L.; Risch, M.; Xu, Z.J.; Shao-Horn, Y. Recommended Practices and Benchmark Activity for Hydrogen and Oxygen Electrocatalysis in Water Splitting and Fuel Cells. Adv. Mater. 2019, 31, e1806296. [CrossRef]

10. King, L.A.; Hubert, M.A.; Capuano, C.; Manco, J.; Danilovic, N.; Valle, E.; Hellstern, T.R.; Ayers, K.; Jaramillo, T.F. A non-precious metal hydrogen catalyst in a commercial polymer electrolyte membrane electrolyser. Nat. Nanotechnol. 2019, 14, 1071-1074. [CrossRef]

11. Kibsgaard, J.; Chorkendorff, I. Considerations for the scaling-up of water splitting catalysts. Nat. Energy 2019, 4, 430-433. [CrossRef]

12. You, B.; Sun, Y. Innovative Strategies for Electrocatalytic Water Splitting. Acc. Chem. Res. 2018, 51, 1571-1580. [CrossRef] [PubMed]

13. Baeumer, C.; Li, J.; Lu, Q.; Liang, A.Y.-L.; Jin, L.; Martins, H.P.; Duchoň, T.; Glöß, M.; Gericke, S.M.; Wohlgemuth, M.A.; et al. Tuning electrochemically driven surface transformation in atomically flat $\mathrm{LaNiO}_{3}$ thin films for enhanced water electrolysis. Nat. Mater. 2021, 20, 674-682. [CrossRef]

14. Wu, C.W.; Zhang, W.; Han, X.; Zhang, Y.X.; Ma, G.J. A systematic review for structure optimization and clamping load design of large proton exchange membrane fuel cell stack. J. Power Sources 2020, 476, 228724. [CrossRef]

15. Choi, C.; Ashby, D.S.; Butts, D.M.; DeBlock, R.H.; Wei, Q.; Lau, J.; Dunn, B. Achieving high energy density and high power density with pseudocapacitive materials. Nat. Rev. Mater. 2020, 5, 5-19. [CrossRef]

16. Montoya, J.H.; Seitz, L.C.; Chakthranont, P.; Vojvodic, A.; Jaramillo, T.F.; Norskov, J.K. Materials for solar fuels and chemicals. Nat. Mater. 2016, 16, 70-81. [CrossRef]

17. Fan, M.; Liang, X.; Chen, H.; Zou, X. Low-iridium electrocatalysts for acidic oxygen evolution. Dalton Trans. 2020, 49, 15568-15573. [CrossRef] [PubMed]

18. Chen, Y.; Li, H.; Wang, J.; Du, Y.; Xi, S.; Sun, Y.; Sherburne, M.; Ager, J.W.; Fisher, A.C.; Xu, Z.J. Exceptionally active iridium evolved from a pseudo-cubic perovskite for oxygen evolution in acid. Nat. Commun. 2019, 10, 572. [CrossRef]

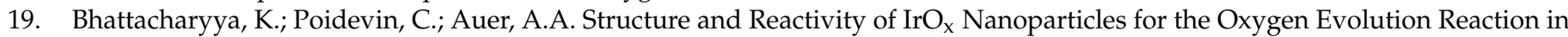
Electrocatalysis: An Electronic Structure Theory Study. J. Phys. Chem. C 2021, 125, 4379-4390. [CrossRef]

20. Huang, Z.-F.; Song, J.; Dou, S.; Li, X.; Wang, J.; Wang, X. Strategies to Break the Scaling Relation toward Enhanced Oxygen Electrocatalysis. Matter 2019, 1, 1494-1518. [CrossRef]

21. Tao, H.B.; Xu, Y.; Huang, X.; Chen, J.; Pei, L.; Zhang, J.; Chen, J.G.; Liu, B. A General Method to Probe Oxygen Evolution Intermediates at Operating Conditions. Joule 2019, 3, 1498-1509. [CrossRef]

22. Li, X.; Zhao, L.; Yu, J.; Liu, X.; Zhang, X.; Liu, H.; Zhou, W. Water Splitting: From Electrode to Green Energy System. Nano-Micro Lett. 2020, 12, 131. [CrossRef]

23. Chen, H.; Shi, L.; Liang, X.; Wang, L.; Asefa, T.; Zou, X. Optimization of Active Sites via Crystal Phase, Composition and Morphology for Efficient Low-Iridium Oxygen Evolution Catalysts. Angew. Chem. Int. Ed. Engl. 2020, 132, 19822-19826. [CrossRef]

24. Gu, X.-K.; Camayang, J.C.A.; Samira, S.; Nikolla, E. Oxygen evolution electrocatalysis using mixed metal oxides under acidic conditions: Challenges and opportunities. J. Catal. 2020, 388, 130-140. [CrossRef]

25. Siwal, S.S.; Yang, W.; Zhang, Q. Recent progress of precious-metal-free electrocatalysts for efficient water oxidation in acidic media. J. Energy Chem. 2020, 51, 113-133. [CrossRef]

26. Song, J.; Wei, C.; Huang, Z.F.; Liu, C.; Zeng, L.; Wang, X.; Xu, Z.J. A review on fundamentals for designing oxygen evolution electrocatalysts. Chem. Soc. Rev. 2020, 49, 2196-2214. [CrossRef]

27. Liu, W.; Liu, H.; Dang, L.; Zhang, H.; Wu, X.; Yang, B.; Li, Z.; Zhang, X.; Lei, L.; Jin, S. Amorphous Cobalt-Iron Hydroxide Nanosheet Electrocatalyst for Efficient Electrochemical and Photo-Electrochemical Oxygen Evolution. Adv. Funct. Mater. 2017, 27, 1603904. [CrossRef]

28. Yin, J.; Jin, J.; Lu, M.; Huang, B.L.; Zhang, H.; Peng, Y.; Xi, P.X.; Yan, C.H. Iridium Single Atoms Coupling with Oxygen Vacancies Boosts Oxygen Evolution Reaction in Acid Media. J. Am. Chem. Soc. 2020, 142, 18378-18386. [CrossRef]

29. Danilovic, N.; Subbaraman, R.; Chang, K.C.; Chang, S.H.; Kang, Y.J.; Snyder, J.; Paulikas, A.P.; Strmcnik, D.; Kim, Y.T.; Myers, D.; et al. Activity-Stability Trends for the Oxygen Evolution Reaction on Monometallic Oxides in Acidic Environments. J. Phys. Chem. Lett. 2014, 5, 2474-2478. [CrossRef]

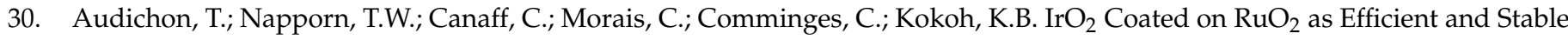
Electroactive Nanocatalysts for Electrochemical Water Splitting. J. Phys. Chem. C 2016, 120, 2562-2573. [CrossRef]

31. Li, G.; Li, S.; Ge, J.; Liu, C.; Xing, W. Discontinuously covered $\mathrm{IrO}_{2}-\mathrm{RuO}_{2} @ \mathrm{Ru}$ electrocatalysts for the oxygen evolution reaction: How high activity and long-term durability can be simultaneously realized in the synergistic and hybrid nano-structure. J. Mater. Chem. A 2017, 5, 17221-17229. [CrossRef]

32. Cao, L.; Luo, Q.; Chen, J.; Wang, L.; Lin, Y.; Wang, H.; Liu, X.; Shen, X.; Zhang, W.; Liu, W.; et al. Dynamic oxygen adsorption on single-atomic Ruthenium catalyst with high performance for acidic oxygen evolution reaction. Nat. Commun. 2019, 10, 4849. [CrossRef]

33. Chandra, D.; Abe, N.; Takama, D.; Saito, K.; Yui, T.; Yagi, M. Open pore architecture of an ordered mesoporous $\mathrm{IrO}_{2}$ thin film for highly efficient electrocatalytic water oxidation. ChemSusChem 2015, 8, 795-799. [CrossRef] 
34. Chen, J.; Cui, P.; Zhao, G.; Rui, K.; Lao, M.; Chen, Y.; Zheng, X.; Jiang, Y.; Pan, H.; Dou, S.X.; et al. Low-Coordinate Iridium Oxide Confined on Graphitic Carbon Nitride for Highly Efficient Oxygen Evolution. Angew. Chem. Int. Ed. 2019, 58, 12540-12544. [CrossRef]

35. Gao, J.; Xu, C.Q.; Hung, S.F.; Liu, W.; Cai, W.; Zeng, Z.; Jia, C.; Chen, H.M.; Xiao, H.; Li, J.; et al. Breaking Long-Range Order in Iridium Oxide by Alkali Ion for Efficient Water Oxidation. J. Am. Chem. Soc. 2019, 141, 3014-3023. [CrossRef]

36. Han, X.B.; Tang, X.Y.; Lin, Y.; Gracia-Espino, E.; Liu, S.G.; Liang, H.W.; Hu, G.Z.; Zhao, X.J.; Liao, H.G.; Tan, Y.Z.; et al. Ultrasmall Abundant Metal-Based Clusters as Oxygen-Evolving Catalysts. J. Am. Chem. Soc. 2019, 141, 232-239. [CrossRef] [PubMed]

37. Liu, G.; Xu, J.; Wang, Y.; Wang, X. An oxygen evolution catalyst on an antimony doped tin oxide nanowire structured support for proton exchange membrane liquid water electrolysis. J. Mater. Chem. A 2015, 3, 20791-20800. [CrossRef]

38. Liang, X.; Shi, L.; Cao, R.; Wan, G.; Yan, W.; Chen, H.; Liu, Y.; Zou, X. Perovskite-Type Solid Solution Nano-Electrocatalysts Enable Simultaneously Enhanced Activity and Stability for Oxygen Evolution. Adv. Mater. 2020, 32, e2001430. [CrossRef]

39. Craig, M.J.; Coulter, G.; Dolan, E.; Soriano-Lopez, J.; Mates-Torres, E.; Schmitt, W.; Garcia-Melchor, M. Universal scaling relations for the rational design of molecular water oxidation catalysts with near-zero overpotential. Nat. Commun. 2019, 10, 4993. [CrossRef]

40. Alia, S.M.; Shulda, S.; Ngo, C.; Pylypenko, S.; Pivovar, B.S. Iridium-Based Nanowires as Highly Active, Oxygen Evolution Reaction Electrocatalysts. ACS Catal. 2018, 8, 2111-2120. [CrossRef]

41. Wu, G.; Zheng, X.; Cui, P.; Jiang, H.; Wang, X.; Qu, Y.; Chen, W.; Lin, Y.; Li, H.; Han, X.; et al. A general synthesis approach for amorphous noble metal nanosheets. Nat. Commun. 2019, 10, 4855. [CrossRef] [PubMed]

42. Yee, D.W.; Lifson, M.L.; Edwards, B.W.; Greer, J.R. Additive Manufacturing of 3D-Architected Multifunctional Metal Oxides. Adv. Mater. 2019, 31, e1901345. [CrossRef]

43. Cheng, J.; Yang, J.; Kitano, S.; Juhasz, G.; Higashi, M.; Sadakiyo, M.; Kato, K.; Yoshioka, S.; Sugiyama, T.; Yamauchi, M.; et al Impact of Ir-Valence Control and Surface Nanostructure on Oxygen Evolution Reaction over a Highly Efficient Ir-TiO $\mathrm{Nanorod}_{2}$ Catalyst. ACS Catal. 2019, 9, 6974-6986. [CrossRef]

44. Shan, J.; Zheng, Y.; Shi, B.; Davey, K.; Qiao, S.-Z. Regulating Electrocatalysts via Surface and Interface Engineering for Acidic Water Electrooxidation. ACS Energy Lett. 2019, 4, 2719-2730. [CrossRef]

45. Sun, W.; Zhou, Z.H.; Zaman, W.Q.; Cao, L.M.; Yang, J. Rational Manipulation of $\mathrm{IrO}_{2}$ Lattice Strain on alpha-MnO 2 Nanorods as a Highly Efficient Water-Splitting Catalyst. ACS Appl. Mater. Interfaces 2017, 9, 41855-41862. [CrossRef]

46. Moon, S.; Cho, Y.B.; Yu, A.; Kim, M.H.; Lee, C.; Lee, Y. Single-Step Electrospun Ir $/ \mathrm{IrO}_{2}$ Nanofibrous Structures Decorated with Au Nanoparticles for Highly Catalytic Oxygen Evolution Reaction. ACS Appl. Mater. Interfaces 2019, 11, 1979-1987. [CrossRef] [PubMed]

47. Massue, C.; Pfeifer, V.; Huang, X.; Noack, J.; Tarasov, A.; Cap, S.; Schlogl, R. High-Performance Supported Iridium Oxohydroxide Water Oxidation Electrocatalysts. ChemSusChem 2017, 10, 1943-1957. [CrossRef] [PubMed]

48. Hornberger, E.; Bergmann, A.; Schmies, H.; Kühl, S.; Wang, G.; Drnec, J.; Sandbeck, D.J.S.; Ramani, V.; Cherevko, S.; Mayrhofer K.J.J.; et al. In Situ Stability Studies of Platinum Nanoparticles Supported on Ruthenium-Titanium Mixed Oxide (RTO) for Fuel Cell Cathodes. ACS Catal. 2018, 8, 9675-9683. [CrossRef]

49. Geiger, S.; Kasian, O.; Ledendecker, M.; Pizzutilo, E.; Mingers, A.M.; Fu, W.T.; Diaz-Morales, O.; Li, Z.; Oellers, T.; Fruchter, L.; et al. The stability number as a metric for electrocatalyst stability benchmarking. Nat. Catal. 2018, 1, 508-515. [CrossRef]

50. Li, G.; Li, K.; Yang, L.; Chang, J.; Ma, R.; Wu, Z.; Ge, J.; Liu, C.; Xing, W. Boosted Performance of Ir Species by Employing TiN as the Support toward Oxygen Evolution Reaction. ACS Appl. Mater. Interfaces 2018, 10, 38117-38124. [CrossRef]

51. Diaz-Morales, O.; Raaijman, S.; Kortlever, R.; Kooyman, P.J.; Wezendonk, T.; Gascon, J.; Fu, W.T.; Koper, M.T.M. Iridium-based double perovskites for efficient water oxidation in acid media. Nat. Commun. 2016, 7, 6. [CrossRef] [PubMed]

52. Barforoush, J.M.; Seuferling, T.E.; Jantz, D.T.; Song, K.R.; Leonard, K.C. Insights into the Active Electrocatalytic Areas of Layered Double Hydroxide and Amorphous Nickel-Iron Oxide Oxygen Evolution Electrocatalysts. ACS Appl. Energy Mater. 2018, 1, 1415-1423. [CrossRef]

53. Shan, J.; Ling, T.; Davey, K.; Zheng, Y.; Qiao, S.Z. Transition-Metal-Doped RuIr Bifunctional Nanocrystals for Overall Water Splitting in Acidic Environments. Adv. Mater. 2019, 31, e1900510. [CrossRef]

54. Shi, Q.; Zhu, C.; Du, D.; Lin, Y. Robust noble metal-based electrocatalysts for oxygen evolution reaction. Chem. Soc. Rev. 2019, 48, 3181-3192. [CrossRef] [PubMed]

55. Lv, L.; Yang, Z.; Chen, K.; Wang, C.; Xiong, Y. 2D Layered Double Hydroxides for Oxygen Evolution Reaction: From Fundamental Design to Application. Adv. Energy Mater. 2019, 9, 1803358. [CrossRef]

56. Grimaud, A.; Diaz-Morales, O.; Han, B.; Hong, W.T.; Lee, Y.L.; Giordano, L.; Stoerzinger, K.A.; Koper, M.T.M.; Shao-Horn, Y. Activating lattice oxygen redox reactions in metal oxides to catalyse oxygen evolution. Nat. Chem. 2017, 9, 457-465. [CrossRef]

57. Nong, H.N.; Tran, H.P.; Spori, C.; Klingenhof, M.; Frevel, L.; Jones, T.E.; Cottre, T.; Kaiser, B.; Jaegermann, W.; Schlogl, R.; et al The Role of Surface Hydroxylation, Lattice Vacancies and Bond Covalency in the Electrochemical Oxidation of Water (OER) on Ni-Depleted Iridium Oxide Catalysts. Z. Fur Phys. Chem.-Int. J. Res. Phys. Chem. Chem. Phys. 2020, 234, 787-812. [CrossRef]

58. Nong, H.N.; Falling, L.J.; Bergmann, A.; Klingenhof, M.; Tran, H.P.; Spori, C.; Mom, R.; Timoshenko, J.; Zichittella, G.; KnopGericke, A.; et al. Key role of chemistry versus bias in electrocatalytic oxygen evolution. Nature 2020, 587, 408-413. [CrossRef] [PubMed] 
59. Stoerzinger, K.A.; Diaz-Morales, O.; Kolb, M.; Rao, R.R.; Frydendal, R.; Qiao, L.; Wang, X.R.; Halck, N.B.; Rossmeisl, J.; Hansen, H.A.; et al. Orientation-Dependent Oxygen Evolution on $\mathrm{RuO}_{2}$ without Lattice Exchange. ACS Energy Lett. $2017,2,876-881$. [CrossRef]

60. Zhang, N.; Feng, X.; Rao, D.; Deng, X.; Cai, L.; Qiu, B.; Long, R.; Xiong, Y.; Lu, Y.; Chai, Y. Lattice oxygen activation enabled by high-valence metal sites for enhanced water oxidation. Nat. Commun. 2020, 11, 4066. [CrossRef] [PubMed]

61. Grimaud, A.; Demortière, A.; Saubanère, M.; Dachraoui, W.; Duchamp, M.; Doublet, M.-L.; Tarascon, J.-M. Activation of surface oxygen sites on an iridium-based model catalyst for the oxygen evolution reaction. Nat. Energy 2016, 2, 16189. [CrossRef]

62. Fu, L.; Yang, F.; Cheng, G.; Luo, W. Ultrathin Ir nanowires as high-performance electrocatalysts for efficient water splitting in acidic media. Nanoscale 2018, 10, 1892-1897. [CrossRef] [PubMed]

63. Jin, Z.; Lv, J.; Jia, H.; Liu, W.; Li, H.; Chen, Z.; Lin, X.; Xie, G.; Liu, X.; Sun, S.; et al. Nanoporous Al-Ni-Co-Ir-Mo High-Entropy Alloy for Record-High Water Splitting Activity in Acidic Environments. Small 2019, 15, e1904180. [CrossRef]

64. Nong, H.N.; Reier, T.; Oh, H.-S.; Gliech, M.; Paciok, P.; Vu, T.H.T.; Teschner, D.; Heggen, M.; Petkov, V.; Schlögl, R.; et al. A unique oxygen ligand environment facilitates water oxidation in hole-doped $\mathrm{IrNiO}_{\mathrm{x}}$ core-shell electrocatalysts. Nat. Catal. 2018, 1, 841-851. [CrossRef]

65. Strickler, A.L.; Flores, R.A.; King, L.A.; Norskov, J.K.; Bajdich, M.; Jaramillo, T.F. Systematic Investigation of Iridium-Based Bimetallic Thin Film Catalysts for the Oxygen Evolution Reaction in Acidic Media. ACS Appl. Mater. Interfaces 2019, 11, 34059-34066. [CrossRef] [PubMed]

66. Lin, Y.; Tian, Z.; Zhang, L.; Ma, J.; Jiang, Z.; Deibert, B.J.; Ge, R.; Chen, L. Chromium-ruthenium oxide solid solution electrocatalyst for highly efficient oxygen evolution reaction in acidic media. Nat. Commun. 2019, 10, 162. [CrossRef]

67. Pi, Y.C.; Shao, Q.; Zhu, X.; Huang, X.Q. Dynamic Structure Evolution of Composition Segregated Iridium-Nickel Rhombic Dodecahedra toward Efficient Oxygen Evolution Electrocatalysis. ACS Nano 2018, 12, 7371-7379. [CrossRef]

68. Reier, T.; Pawolek, Z.; Cherevko, S.; Bruns, M.; Jones, T.; Teschner, D.; Selve, S.; Bergmann, A.; Nong, H.N.; Schlogl, R.; et al. Molecular Insight in Structure and Activity of Highly Efficient, Low-Ir Ir-Ni Oxide Catalysts for Electrochemical Water Splitting (OER). J. Am. Chem. Soc. 2015, 137, 13031-13040. [CrossRef]

69. Bele, M.; Stojanovski, K.; Jovanovič, P.; Moriau, L.; Koderman Podboršek, G.; Moškon, J.; Umek, P.; Sluban, M.; Dražič, G.; Hodnik, N.; et al. Towards Stable and Conductive Titanium Oxynitride High-Surface-Area Support for Iridium Nanoparticles as Oxygen Evolution Reaction Electrocatalyst. Chem CatChem 2019, 11, 5038-5044. [CrossRef]

70. Ge, R.; Li, L.; Su, J.; Lin, Y.; Tian, Z.; Chen, L. Ultrafine Defective RuO2 Electrocatayst Integrated on Carbon Cloth for Robust Water Oxidation in Acidic Media. Adv. Energy Mater. 2019, 9, 1901313. [CrossRef]

71. Kwon, J.; Han, H.; Choi, S.; Park, K.; Jo, S.; Paik, U.; Song, T. Current Status of Self-Supported Catalysts for Robust and Efficient Water Splitting for Commercial Electrolyzer. ChemCatChem 2019, 11, 5898-5912. [CrossRef]

72. Zhang, B.; Zheng, X.L.; Voznyy, O.; Comin, R.; Bajdich, M.; Garcia-Melchor, M.; Han, L.L.; Xu, J.X.; Liu, M.; Zheng, L.R.; et al. Homogeneously dispersed multimetal oxygen-evolving catalysts. Science 2016, 352, 333-337. [CrossRef] [PubMed]

73. Dong, C.; Li, Y.; Cheng, D.; Zhang, M.; Liu, J.; Wang, Y.-G.; Xiao, D.; Ma, D. Supported Metal Clusters: Fabrication and Application in Heterogeneous Catalysis. ACS Catal. 2020, 10, 11011-11045. [CrossRef]

74. Li, X.; Yang, X.; Huang, Y.; Zhang, T.; Liu, B. Supported Noble-Metal Single Atoms for Heterogeneous Catalysis. Adv. Mater. 2019, 31, e1902031. [CrossRef]

75. Lou, Y.; Xu, J.; Zhang, Y.; Pan, C.; Dong, Y.; Zhu, Y. Metal-support interaction for heterogeneous catalysis: From nanoparticles to single atoms. Mater. Today Nano 2020, 12, 100093. [CrossRef]

76. Chen, P.; Lu, J.; Xie, G.; Zhu, L.; Luo, M. Characterizations of Ir/ $\mathrm{TiO}_{2}$ catalysts with different Ir contents for selective hydrogenation of crotonaldehyde. React. Kinet. Mech. Catal. 2012, 106, 419-434. [CrossRef]

77. $\mathrm{Xu}$, J.; Liu, G.; Li, J.; Wang, X. The electrocatalytic properties of an $\mathrm{IrO}_{2} / \mathrm{SnO}_{2}$ catalyst using $\mathrm{SnO}$ as a support and an assisting reagent for the oxygen evolution reaction. Electrochim. Acta 2012, 59, 105-112. [CrossRef]

78. $\mathrm{Wu}, \mathrm{X}$; Scott, $\mathrm{K} . \mathrm{RuO}_{2}$ supported on $\mathrm{Sb}$-doped $\mathrm{SnO}_{2}$ nanoparticles for polymer electrolyte membrane water electrolysers. Int. J. Hydrog. Energy 2011, 36, 5806-5810. [CrossRef]

79. Polonsky, J.; Mazur, P.; Paidar, M.; Christensen, E.; Bouzek, K. Performance of a PEM water electrolyser using a TaC-supported iridium oxide electrocatalyst. Int. J. Hydrog. Energy 2014, 39, 3072-3078. [CrossRef]

80. Ma, L.; Sui, S.; Zhai, Y. Preparation and characterization of Ir/TiC catalyst for oxygen evolution. J. Power Sources 2008, 177, 470-477. [CrossRef]

81. Jiang, B.; Wang, T.; Cheng, Y.; Liao, F.; Wu, K.; Shao, M. Ir/g- $\mathrm{C}_{3} \mathrm{~N}_{4}$ /Nitrogen-Doped Graphene Nanocomposites as Bifunctional Electrocatalysts for Overall Water Splitting in Acidic Electrolytes. ACS Appl. Mater. Interfaces 2018, 10, 39161-39167. [CrossRef] [PubMed]

82. Yang, C.; Rousse, G.; Louise Svane, K.; Pearce, P.E.; Abakumov, A.M.; Deschamps, M.; Cibin, G.; Chadwick, A.V.; Dalla Corte, D.A.; Anton Hansen, H.; et al. Cation insertion to break the activity/stability relationship for highly active oxygen evolution reaction catalyst. Nat. Commun. 2020, 11, 1378. [CrossRef] [PubMed]

83. Zaman, W.Q.; Wang, Z.Q.; Sun, W.; Zhou, Z.H.; Tariq, M.; Cao, L.M.; Gong, X.Q.; Yang, J. Ni-Co Codoping Breaks the Limitation of Single-Metal-Doped $\mathrm{IrO}_{2}$ with Higher Oxygen Evolution Reaction Performance and Less Iridium. ACS Energy Lett. 2017, 2, 2786-2793. [CrossRef] 
84. Kim, J.; Shih, P.C.; Tsao, K.C.; Pan, Y.T.; Yin, X.; Sun, C.J.; Yang, H. High-Performance Pyrochlore-Type Yttrium Ruthenate Electrocatalyst for Oxygen Evolution Reaction in Acidic Media. J. Am. Chem. Soc. 2017, 139, 12076-12083. [CrossRef] [PubMed]

85. Kim, B.J.; Abbott, D.F.; Cheng, X.; Fabbri, E.; Nachtegaal, M.; Bozza, F.; Castelli, I.E.; Lebedev, D.; Schaublin, R.; Coperet, C.; et al. Unraveling Thermodynamics, Stability, and Oxygen Evolution Activity of Strontium Ruthenium Perovskite Oxide. ACS Catal. 2017, 7, 3245-3256. [CrossRef]

86. Retuerto, M.; Pascual, L.; Calle-Vallejo, F.; Ferrer, P.; Gianolio, D.; Pereira, A.G.; Garcia, A.; Torrero, J.; Fernandez-Diaz, M.T.; Bencok, P.; et al. Na-doped ruthenium perovskite electrocatalysts with improved oxygen evolution activity and durability in acidic media. Nat. Commun. 2019, 10, 9. [CrossRef]

87. Seitz, L.C.; Dickens, C.F.; Nishio, K.; Hikita, Y.; Montoya, J.; Doyle, A.; Kirk, C.; Vojvodic, A.; Hwang, H.Y.; Norskov, J.K.; et al. A highly active and stable $\mathrm{IrO}_{x} / \mathrm{SrIrO}_{3}$ catalyst for the oxygen evolution reaction. Science 2016, 353, 1011-1014. [CrossRef] [PubMed]

88. Zhu, J.; Chen, Z.; Xie, M.; Lyu, Z.; Chi, M.; Mavrikakis, M.; Jin, W.; Xia, Y. Iridium-Based Cubic Nanocages with 1.1-nm-Thick Walls: A Highly Efficient and Durable Electrocatalyst for Water Oxidation in an Acidic Medium. Angew. Chem. Int. Ed. 2019, 58, 7244-7248. [CrossRef]

89. Song, C.W.; Suh, H.; Bak, J.; Bae, H.B.; Chung, S.Y. Dissolution-Induced Surface Roughening and Oxygen Evolution Electrocatalysis of Alkaline-Earth Iridates in Acid. Chem 2019, 5, 3243-3259. [CrossRef]

90. Yang, L.; Yu, G.T.; Ai, X.; Yan, W.S.; Duan, H.L.; Chen, W.; Li, X.T.; Wang, T.; Zhang, C.H.; Huang, X.R.; et al. Efficient oxygen evolution electrocatalysis in acid by a perovskite with face-sharing $\mathrm{IrO}_{6}$ octahedral dimers. Nat. Commun. 2018, 9, 9. [CrossRef]

91. Liang, X.; Shi, L.; Liu, Y.P.; Chen, H.; Si, R.; Yan, W.S.; Zhang, Q.; Li, G.D.; Yang, L.; Zou, X.X. Activating Inert, Nonprecious Perovskites with Iridium Dopants for Efficient Oxygen Evolution Reaction under Acidic Conditions. Angew. Chem.-Int. Ed. 2019, 58, 7631-7635. [CrossRef]

92. Kaiser, S.K.; Chen, Z.; Faust Akl, D.; Mitchell, S.; Perez-Ramirez, J. Single-Atom Catalysts across the Periodic Table. Chem. Rev. 2020, 120, 11703-11809. [CrossRef]

93. Tamaki, T.; Wang, H.; Oka, N.; Honma, I.; Yoon, S.-H.; Yamaguchi, T. Correlation between the carbon structures and their tolerance to carbon corrosion as catalyst supports for polymer electrolyte fuel cells. Int. J. Hydrog. Energy 2018, 43, 6406-6412. [CrossRef]

94. Yao, Y.C.; Hu, S.L.; Chen, W.X.; Huang, Z.Q.; Wei, W.C.; Yao, T.; Liu, R.R.; Zang, K.T.; Wang, X.Q.; Wu, G.; et al. Engineering the electronic structure of single atom Ru sites via compressive strain boosts acidic water oxidation electrocatalysis. Nat. Catal. 2019, 2, 304-313. [CrossRef]

95. Luo, Z.; Zhang, H.; Yang, Y.; Wang, X.; Li, Y.; Jin, Z.; Jiang, Z.; Liu, C.; Xing, W.; Ge, J. Reactant friendly hydrogen evolution interface based on di-anionic $\mathrm{MoS}_{2}$ surface. Nat. Commun. 2020, 11, 1116. [CrossRef]

96. Lu, Z.-X.; Shi, Y.; Gupta, P.; Min, X.-P.; Tan, H.-Y.; Wang, Z.-D.; Guo, C.-Q.; Zou, Z.-Q.; Yang, H.; Mukerjee, S.; et al. Electrochemical fabrication of $\mathrm{IrO}_{\mathrm{x}}$ nanoarrays with tunable length and morphology for solid polymer electrolyte water electrolysis. Electrochim. Acta 2020, 348, 136302. [CrossRef]

97. Ortel, E.; Reier, T.; Strasser, P.; Kraehnert, R. Mesoporous $\mathrm{IrO}_{2}$ Films Templated by PEO-PB-PEO Block-Copolymers: Self-Assembly, Crystallization Behavior, and Electrocatalytic Performance. Chem. Mater. 2011, 23, 3201-3209. [CrossRef]

98. Li, G.; Li, S.; Xiao, M.; Ge, J.; Liu, C.; Xing, W. Nanoporous $\mathrm{IrO}_{2}$ catalyst with enhanced activity and durability for water oxidation owing to its micro/mesoporous structure. Nanoscale 2017, 9, 9291-9298. [CrossRef]

99. Shan, J.Q.; Guo, C.X.; Zhu, Y.H.; Chen, S.M.; Song, L.; Jaroniec, M.; Zheng, Y.; Qiao, S.Z. Charge-Redistribution-Enhanced Nanocrystalline Ru@IrO $\mathrm{I}_{\mathrm{x}}$ Electrocatalysts for Oxygen Evolution in Acidic Media. Chem 2019, 5, 445-459. [CrossRef]

100. Laha, S.; Lee, Y.; Podjaski, F.; Weber, D.; Duppel, V.; Schoop, L.M.; Pielnhofer, F.; Scheurer, C.; Muller, K.; Starke, U.; et al. Ruthenium Oxide Nanosheets for Enhanced Oxygen Evolution Catalysis in Acidic Medium. Adv. Energy Mater. 2019, 9, 8. [CrossRef] 